\title{
Prevalence, Awareness, Treatment and Control of Coexistence of Diabetes and Hypertension in Thai Population
}

\author{
Siriwat Tiptaradol ${ }^{1}$ and Wichai Aekplakorn ${ }^{2}$ \\ ${ }^{1}$ Office of Permanent Secretary, Ministry of Public Health, Nonthaburi 11000, Thailand \\ ${ }^{2}$ Department of Community Medicine, Faculty of Medicine, Ramathibodi Hospital, Mahidol University, \\ Rama VI Road, Rajdevi, Bangkok 10400, Thailand
}

Correspondence should be addressed to Wichai Aekplakorn, wichai.aek@mahidol.ac.th

Received 9 May 2012; Accepted 5 June 2012

Academic Editor: Yackoob Kassim Seedat

Copyright ( $\odot 2012$ S. Tiptaradol and W. Aekplakorn. This is an open access article distributed under the Creative Commons Attribution License, which permits unrestricted use, distribution, and reproduction in any medium, provided the original work is properly cited.

Diabetes and hypertension are major independent risk factors for cardiovascular and renal diseases; however, prevalence and characteristics of the coexistence in general population is not clear. Data from Thai National Health Examination Survey III were used to estimate the prevalence of coexistence of diabetes and hypertension, and to estimate the proportion of awareness, treatment and control of both conditions. A total of 36,877 (male 17,614 and female 19,263) participants were included in the study. The prevalence of people with diabetes and hypertension was 3.2\% (male $2.8 \%$ and female $3.6 \%$ ). Approximately half of the diabetes patients $(49.0 \%, 95 \%$ CI $45.6,52.5)$ had hypertension, and 14.4\% (95\%CI 13.0, 16.0) of hypertensive patients had diabetes. After controlling for covariates, factors associated with coexistence of diabetes and hypertension included; age $\geq 60$ years (adjust odds ratio $1.38,95 \%$ CI $1.14,1.73)$, having education less than 6 years $(1.83,95 \%$ CI $1.03,3.38)$ and abdominal obesity $(2.49,95 \%$ CI $2.00,3.10$ ). More than $80 \%$ were unaware of having both conditions. Target for control of both glucose and blood pressure among those treated was achieved in only $6.2 \%$. In conclusion, patients with diabetes or hypertension should be promoted to have weight control and screening for the comorbidity.

\section{Introduction}

At present, diabetes and hypertension are among the most common noncommunicable chronic diseases in developed and developing countries around the world [1]. In Thailand, burden of diseases defined as total disability-adjusted life year (DALY) loss attributed to diabetes was 1.7 million years $(3.1 \%)$ in men and 2.7 million years $(6.4 \%)$ in women, and to hypertension was $5.5 \%$ each in both men and women [2]. Hypertension is commonly found in patients with diabetes and vice versa. People with coexisting diabetes and hypertension are at increased risk of atherosclerosis, retinopathy, renal failure and nontraumatic amputations, and cardiovascular diseases $[3,4]$. These conditions not only result in high burden to the patients and family, but also impose a high national health care cost worldwide. In Thailand, the 2004 National Health Examination survey
(NHES III) reported the prevalence of $6.8 \%$ and $21.0 \%$ for diabetes and hypertension, respectively, in Thai population aged $\geq 15$ years $[1,5]$. These studies also revealed that more than half of individuals with the each condition were unaware of the condition. Furthermore, the percentages of the patients who were treated and controlled to target levels were substantially low. Although there has been certain information on proportions of patients with both conditions [1], the characteristics of individuals with the coexistence of both conditions have not been clearly identified. Moreover, knowing factors associated with the conditions should be useful for health service and public health action in term management and prevention. The present study aimed to determine the prevalence of coexistence of diabetes and hypertension and the proportions of awareness, treatment, and control of the coexistence of both conditions in Thai population by using data from the NHES III. 


\section{Methods}

2.1. Study Population. The sampling method and data collection procedures of NHES III were described elsewhere $[5,6]$. Briefly, the national health examination survey is a multistage probability sampling of Thai population aged $\geq 15$ years. The sampling unit in each of the four stages of selection included: (1) three provinces in each of the 12 public health regions; (2) nine electoral units (EUs) or villages from urban and rural areas, respectively; and (3) 15 individuals from each EU or village. The final sample size was targeted at 42,120 individuals and the final complete data used for analysis of this study was 36,877 individuals (male 17,614 and female 19,263 ) aged $\geq 15$ years.

2.2. Data Collection. Data on demographic characteristics, lifestyle behavior, history of diabetes and hypertension, and management were interviewed by trained interviewers. Blood pressure was measured by trained field staff according to standard protocol [7]. Three serial measurements of blood pressure, taken 1 minute apart, were obtained using a mercury sphygmomanometer with subjects in the sitting position after $5 \mathrm{~min}$ of rest. Weight, height, and waist circumference (WC) were measured by trained field staff using standard procedures and equipment according to the World Health Organization guideline [8]. Subjects wore light clothing but without shoes while their height and weight were measured. WC was measured at a level midway between lower rib margin and iliac crest with a measuring tape on a horizontal plane around the body [8].

Venous blood samples were obtained in the morning after the participants had fasted overnight. Fasting plasma glucose (FPG) was tested using hexokinase enzyme method. Serum cholesterol was measured suing enzymatic methods. The laboratory centers were a standardized central laboratory at the Ministry of Public Health.

2.3. Definitions. Blood pressure was the average of two serial blood-pressure measurements with lowest variability in pulse pressure. Hypertension was defined as a systolic $(\mathrm{SBP}) \geq 140 \mathrm{mmHg}$ or a diastolic blood pressure (DBP) $\geq 90 \mathrm{mmHg}$ or on medication with blood-lowering agents during the past 2 weeks [7]. Diabetes was defined as FPG $\geq 7.0 \mathrm{mmol} / \mathrm{L}(\geq 126 \mathrm{mg} / \mathrm{dL})$ or previous diagnosis and on treatment of diabetes using antiglycemic agents or insulin during the past 2 weeks [1,9]. Diagnosed diabetes was defined as those who were diagnosed by medical doctors and were on treatment with antiglycemic drugs in the past 2 weeks. Individuals reported on receiving antiglycemic drugs in the past two weeks were considered as on treatment. Individuals on diabetes treatment were considered as being controlled if their FPG was less than $130 \mathrm{mg} / \mathrm{dL}$ [10]. Control target of blood pressure was set at SBP $<140 \mathrm{mmHg}$ and DBP $<90 \mathrm{mmHg}$ for hypertensive individuals without diabetes, and $\mathrm{SBP}<130 \mathrm{mmHg}$ and $\mathrm{DBP}<90 \mathrm{mmHg}$ for those with coexistence of hypertension and diabetes [9]. Asian criteria for obesity was used at cut-off point of BMI $\geq 25 \mathrm{~kg} / \mathrm{m}^{2}$ and

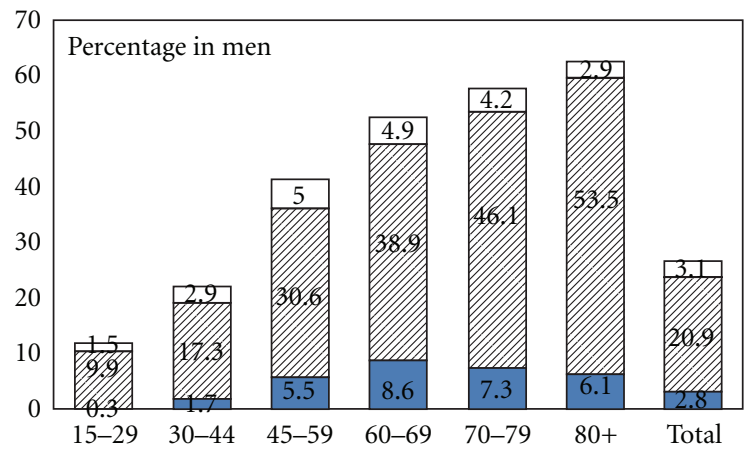

(a)

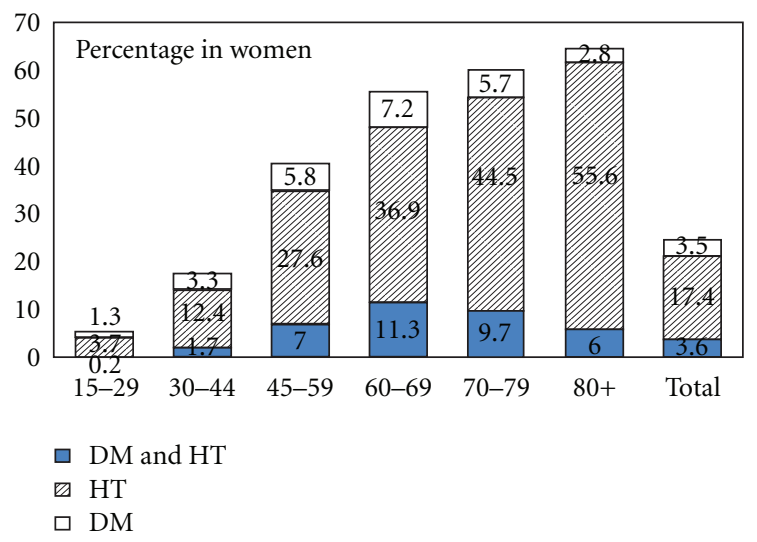

(b)

Figure 1: Prevalence of diabetes, hypertension, and coexistence of both conditions in Thai population aged $\geq 15$ years by age group.

abdominal obesity was defined as $\mathrm{WC} \geq 90 \mathrm{~cm}$. for male and $\geq 80 \mathrm{~cm}$ for female [11].

2.4. Statistical Methods. All the analyses were weighted against the registered 2004 Thai population by public health administration area, urban/rural areas, sex, and 5-year age groups. The analysis was accounted for the complex survey design using "svy" command in Stata software version 10. Subjects were categorized into 4 groups: no diabetes or hypertension, diabetes only, hypertension only, and those with coexistence of diabetes and hypertension. Mean values and $95 \%$ confidence interval (CI) for continuous variables were calculated. Prevalence of diabetes, hypertension alone, and the coexistence as well as awareness and treatment of those having the conditions were calculated. The proportion of the controlled was calculated among those who were treated. Multivariable logistic regression was used to examine the association of several independent variables including age, sex, urban/rural and educational level, obesity (BMI $\geq$ $25 \mathrm{~kg} / \mathrm{m}^{2}$ ), and abdominal obesity with the coexistence of diabetes and hypertension.

\section{Results}

The prevalence of diabetes alone, hypertension alone, and the coexistence of both was 3.3\% (95\%CI 2.8, 4.0), $19.1 \%$ 
TABLE 1: Characteristics of participants with diabetes, hypertension and coexistence of both conditions in Thai population aged $\geq 15$ years, 2004.

\begin{tabular}{|c|c|c|c|c|c|}
\hline & $\begin{array}{c}\text { No DM and no HT } \\
\quad(n=20,906)\end{array}$ & $\begin{array}{c}\text { DM only } \\
(n=1,715) \\
\end{array}$ & $\begin{array}{c}\text { HT only } \\
(n=11,708)\end{array}$ & $\begin{array}{l}\text { DM and HT } \\
(n=2,548)\end{array}$ & $P$ value \\
\hline Male & $n=9,867$ & $n=724$ & $n=5,923$ & $n=1,100$ & \\
\hline Age (yr) & $35.7(35.3,36.2)$ & $45.3(42.5,48.1)$ & $48.3(47.1,49.4)$ & $54.9(52.9,57.0)$ & $<0.01$ \\
\hline BMI $\left(\mathrm{kg} / \mathrm{m}^{2}\right)$ & $22.1(21.9,22.3)$ & $23.3(22.4,24.2)$ & $24.2(23.8,24.7)$ & $27.0(25.5,28.5)$ & $<0.01$ \\
\hline Waist (cm) & $77.2(76.6,77.7)$ & $81.8(80.3,83.4)$ & $82.9(81.8,84.1)$ & $90.9(87.0,94.8)$ & $<0.01$ \\
\hline $\mathrm{FPG}(\mathrm{mg} / \mathrm{dL})$ & $89.2(88.2,90.2)$ & $170.9(165.9,175.9)$ & $91.4(90.1,92.7)$ & $185.1(173.5,196.6)$ & $<0.01$ \\
\hline $\mathrm{SBP}(\mathrm{mmHg})$ & $114.0(113.5,114.6)$ & $115.6(113.9,117.4)$ & $137.8(136.3,139.4)$ & $139.0(137.3,140.8)$ & $<0.01$ \\
\hline $\mathrm{TC}(\mathrm{mg} / \mathrm{dL})$ & $185.8(183.5,188.2)$ & $194.4(178.9,209.8)$ & $198.0(194.1,201.8)$ & $201.9(181.1,222.8)$ & $<0.01$ \\
\hline $\mathrm{TC} \geq 240(\%)$ & $11.6(10.4,12.9)$ & $20.1(15.5,25.5)$ & $18.5(15.5,22.0)$ & $38.0(31.3,45.0)$ & $<0.01$ \\
\hline $\mathrm{BMI} \geq 25(\%)$ & $17.9(16.2,19.7)$ & $30.5(23.6,38.4)$ & $36.6(32.7,40.6)$ & $57.2(47.2,66.7)$ & $<0.01$ \\
\hline Abdominal obesity (\%) & $11.0(9.8,12.3)$ & $24.9(19.2,31.6)$ & $26.6(23.3,30.2)$ & $50.4(39.8,61.0)$ & $<0.01$ \\
\hline Female & $n=11,039$ & $n=991$ & $n=5,785$ & $n=1,448$ & $<0.01$ \\
\hline Age (yr) & $36.1(35.6,36.6)$ & $49.1(47.1,51.2)$ & $53.9(53.0,54.8)$ & $56.6(55.4,57.9)$ & $<0.01$ \\
\hline BMI $\left(\mathrm{kg} / \mathrm{m}^{2}\right)$ & $23.3(23.1,23.4)$ & $25.2(24.3,26.2)$ & $25.6(25.1,26.3)$ & $29.4(28.3,30.5)$ & $<0.01$ \\
\hline Waist (cm) & $75.2(74.6,75.8)$ & $81.7(79.2,84.2)$ & $80.7(79.4,82.0)$ & $90.7(88.7,92.6)$ & $<0.01$ \\
\hline $\mathrm{FPG}(\mathrm{mg} / \mathrm{dL})$ & $86.6(85.6,87.5)$ & $181.7(168.5,194.9)$ & $88.8(87.6,89.9)$ & $172.8(163.4,182.2)$ & $<0.01$ \\
\hline $\mathrm{SBP}(\mathrm{mm} \mathrm{Hg})$ & $110.9(110.3,111.5)$ & $113.5(112.1,115.0)$ & $136.6(135.0,138.1)$ & $144.9(143.3,146.5)$ & $<0.01$ \\
\hline $\mathrm{TC}(\mathrm{mg} / \mathrm{dL})$ & $194.6(192.2,197.0)$ & $195.1(176.6,213.5)$ & $203.9(198.8,209.0)$ & $221.1(213.0,229.2)$ & $<0.01$ \\
\hline $\mathrm{TC} \geq 240(\%)$ & $14.2(12.9,15.6)$ & $27.8(19.0,38.6)$ & $21.0(18.2,24.1)$ & $42.2(38.96,45.5)$ & $<0.01$ \\
\hline $\mathrm{BMI} \geq 25(\%)$ & $30.1(28.6,31.7)$ & $45.08(37.4,53.0)$ & $52.2(47.0,57.2)$ & $63.6(56.7,69.9)$ & $<0.01$ \\
\hline Abdominal obesity (\%) & $31.0(29.0,33.0)$ & $51.1(43.3,58.9)$ & $51.4(46.6,56.2)$ & $84.3(81.0,84.3)$ & $<0.01$ \\
\hline
\end{tabular}

Data were mean and percent (\%) as specified; DM: diabetes; HT: hypertension; BMI: body mass index; FPG: fasting plasma glucose; SBP: systolic blood pressure; TC: total cholesterol; Abdominal obesity, waist circumference $\geq 90 \mathrm{~cm}$ in men and $\geq 80 \mathrm{~cm}$ in women.

$(17.6,20.6)$, and $3.2 \%(2.9,3.6)$, respectively. The prevalence of the coexistence was higher in women $(3.6 \%, 95 \% \mathrm{CI} 3.2$, 4.0) than in men $(2.8 \%$, 95\%CI $2.4,3.3)(P<0.05)$. Approximately half of the patients with diabetes $(49.0 \%$, 95\%CI 45.6, 52.5) had hypertension, while $14.4 \%$ (95\%CI $13.0,16.0)$ of hypertensive individuals had diabetes.

Subjects with the coexistence were older, having higher BMI, larger waist circumference, higher systolic blood pressure, and higher level of blood total cholesterol compared to those having diabetes alone or hypertension alone. The proportion of participants with high cholesterol (TC $\geq$ $240 \mathrm{mg} / \mathrm{dL}$ ) was also highest in those with the coexistence, followed by those with diabetes. People with the coexistence also had highest rates of obesity, followed by those having hypertension alone (Table 1). The prevalence of the coexistence was significantly higher in those with BMI $\geq 25 \mathrm{~kg} / \mathrm{m}^{2}$ than in those with BMI $<25 \mathrm{~kg} / \mathrm{m}^{2}(6.2 \%$ versus $2.0 \%$, resp., $P<0.01)$ as well as higher in those with abdominal obesity than in those without $(7.7 \%$ versus $1.6 \%$, resp., $P<0.01)$.

Figure 1 shows the prevalence of diabetes alone, hypertension alone and the coexistence of both conditions by age groups. The age-specific prevalence of individuals having either conditions or both conditions increased as age increased and peaked at age 80 and over. Prevalence of coexistence of both conditions was highest in the group 6069 years (8.6\% in men and $11.3 \%$ in women).
3.1. Urban/Rural and Geographic Difference. The prevalence of the coexistence of both conditions was significantly higher in urban men than rural men $(3.9$ versus $2.4 \%, P<0.05)$ but not significantly different between urban and rural women (3.9 versus $3.5 \% P>0.05)$. People in Bangkok had the highest prevalence of the coexistence for both men and women, followed by men in central region and women in the northeastern region (Table 2).

3.2. Awareness, Treatment, and Control. Table 3 shows the proportion of awareness diabetes, treatment, and control of fasting plasma glucose, high blood pressure, or both among individuals with coexistence of both conditions. Approximately half of the people with the coexistence were unaware of either one condition and $85 \%$ of them were unaware of having both conditions. More people were not treated for hypertension compared to treatment for diabetes. Less than $20 \%$ of the individuals were controlled for each condition, and only $6.2 \%$ of those with both conditions and treated had their blood glucose and blood pressure under control (Table 3).

3.3. Factors Associated with Comorbidity of Diabetes and Hypertension. Table 4 shows factors that were associated with the coexistence compared to those with having either 
TABLE 2: Prevalence (95\%CI) of diabetes, hypertension and coexistence of both conditions by area of residence and region in Thai population aged $\geq 15$ years.

\begin{tabular}{|c|c|c|c|}
\hline & $\begin{array}{c}\text { DM only } \\
\%(95 \% \mathrm{CI})\end{array}$ & $\begin{array}{c}\text { HT only } \\
\%(95 \% \mathrm{CI})\end{array}$ & $\begin{array}{c}\text { Coexistence of both } \\
\%(95 \% \mathrm{CI})\end{array}$ \\
\hline \multicolumn{4}{|l|}{ Male } \\
\hline Urban & $3.8(3.1,4.7)$ & $22.8(20.6,25.2)$ & $3.9(3.4,4.5)$ \\
\hline Rural & $2.8(2.1,3.9)$ & $20.2(18.1,22.6)$ & $2.4(1.9,3.0)$ \\
\hline \multicolumn{4}{|l|}{ Region } \\
\hline Central & $2.8(2.3,3.6)$ & $22.2(19.5,25.3)$ & $3.2(2.7,3.8)$ \\
\hline Northeastern & $3.7(2.3,5.1)$ & $18.6(14.9,23.0)$ & $2.6(1.7,3.8)$ \\
\hline North & $2.4(1.8,3.3)$ & $25.1(21.2,29.4)$ & $2.6(2.0,3.4)$ \\
\hline South & $2.4(1.4,4.3)$ & $17.9(15.6,20.5)$ & $2.2(1.6,3.0)$ \\
\hline Bangkok & $4.3(3.1,5.8)$ & $17.5(14.3,21.1)$ & $5.2(3.8,7.0)$ \\
\hline \multicolumn{4}{|l|}{ Female } \\
\hline Urban & $3.4(2.9,4.0)$ & $18.0(16.5,19.6)$ & $3.9(3.5,4.3)$ \\
\hline Rural & $3.6(3.0,4.5)$ & $17.2(15.8,18.7)$ & $3.5(3.1,4.0)$ \\
\hline \multicolumn{4}{|l|}{ Region } \\
\hline Central & $3.2(2.5,4.1)$ & $19.2(17.3,21.3)$ & $3.4(3.0,4.0)$ \\
\hline North eastern & $4.5(3.3,6.1)$ & $16.0(13.8,18.4)$ & $3.9(3.1,4.8)$ \\
\hline North & $3.0(2.4,3.7)$ & $19.2(16.1,22.6)$ & $3.6(2.9,4.4)$ \\
\hline South & $2.9(2.3,3.7)$ & $15.0(13.3,16.8)$ & $3.0(2.2,4.1)$ \\
\hline Bangkok & $3.9(2.6,5.9)$ & $14.6(12.9,16.5)$ & $4.4(3.6,5.4)$ \\
\hline
\end{tabular}

TABLe 3: Proportion of awareness, treated, and controlled of those having diabetes, hypertension, and coexistence of both conditions in Thai population aged $\geq 15$ years.

\begin{tabular}{|c|c|c|c|}
\hline & $\begin{array}{c}\text { Male } \\
\%(95 \% \mathrm{CI})\end{array}$ & $\begin{array}{c}\text { Female } \\
\%(95 \% \mathrm{CI})\end{array}$ & $\begin{array}{c}\text { Total } \\
\%(95 \% \mathrm{CI})\end{array}$ \\
\hline \multicolumn{4}{|l|}{ Diabetes only } \\
\hline Aware & $43.3(37.1,49.8)$ & $61.9(55.4,68.0)$ & $54.1(48.3,59.8)$ \\
\hline Treated & $40.8(34.9,47.0)$ & $60.2(53.9,66.2)$ & $52.1(46.5,57.6)$ \\
\hline Controlled among treated & $33.2(27.1,40.0)$ & $38.1(32.4,44.0)$ & $36.5(32.4,40.7)$ \\
\hline \multicolumn{4}{|l|}{ Hypertension only } \\
\hline Aware & $43.0(36.7,49.5)$ & $52.3(46.1,58.5)$ & $48.4(43.0,53.9)$ \\
\hline Treated & $36.4(30.5,42.7)$ & $46.0(39.7,52.1)$ & $42.0(36.9,47.3)$ \\
\hline Controlled among treated & $12.2(8.3,17.5)$ & $16.5(11.7,22.7)$ & $14.9(11.4,19.3)$ \\
\hline \multicolumn{4}{|l|}{ Coexistence of both } \\
\hline Aware & $26.6(21.9,32.0)$ & $39.3(33.5,45.3)$ & $34.0(29.4,38.9)$ \\
\hline Treated & $22.4(18.6,26.7)$ & $34.6(29.0,40.7)$ & $29.5(25.3,34.1)$ \\
\hline Controlled among treated & $2.6(1.4,4.6)$ & $7.8(4.5,13.4)$ & $6.2(3.8,9.9)$ \\
\hline
\end{tabular}

Controlled target of FPG for those with diabetes alone: FPG at $<130 \mathrm{mg} / \mathrm{dL}$.

Controlled target of blood pressure for those with hypertension alone: SBP/DBP at $<140 / 90 \mathrm{~mm} \mathrm{Hg}$.

Controlled target of blood pressure for those having coexistence of diabetes and hypertension: SBP/DBP at $<130 / 80 \mathrm{~mm} \mathrm{Hg}$.

diabetes or hypertension alone. After controlling for potential confounding factors of sociodemographic variables including age, sex, education, urban/rural are as, geographic region, obesity $\left(\mathrm{BMI} \geq 25 \mathrm{~kg} / \mathrm{m}^{2}\right)$, and abdominal obesity, factors that were associated with the coexistence of both conditions included: age $\geq 60$ years (adjusted odds ratio (OR) $1.38,95 \%$ CI $1.14,1.70)$, living in urban area $(1.15$, $95 \%$ CI $1.0,1.30)$, having education less than 6 years $(1.83$, $95 \% \mathrm{CI} 1.03,3.38)$, and abdominal obesity $(2.49,95 \% \mathrm{CI}$
$2.00,3.10)$. Note that $\mathrm{BMI} \geq 25 \mathrm{~kg} / \mathrm{m}^{2}$ was not significantly associated with the coexistence in the multivariable model. Additional analysis for multivariable logistic regression was performed using BMI cut-off point at $30 \mathrm{~kg} / \mathrm{m}^{2}$, instead of at $25 \mathrm{~kg} / \mathrm{m}^{2}$. The results showed that BMI $\geq 30 \mathrm{~kg} / \mathrm{m}^{2}$ still was not significantly associated with the coexistence of diabetes and hypertension (adjusted OR 1.17, 95\%CI 0.91, 1.50), whereas abdominal obesity remains statistically significance $(2.50,95 \%$ CI $2.01,2.97)$. 
TABLE 4: Factors associated with coexistence of hypertension and diabetes compared to those having either diabetes or hypertension alone.

\begin{tabular}{lcc}
\hline & Unadjusted OR & Adjusted OR* \\
\hline Female (versus male $=0)$ & $1.48(1.26,1.73)$ & $1.02(0.85,1.20)$ \\
Age $\geq 60$ years $($ aged $15-<59$ yrs $=0)$ & $1.50(1.30,1.74)$ & $1.38(1.14,1.70)$ \\
Urban (versus rural $=0$ ) & $1.22(1.03,1.45)$ & $1.15(1.00,1.30)$ \\
Education (versus no formal education $=0)$ & \\
$\quad$ less than 6 year & $1.93(1.09,3.42)$ & $1.83(1.03,3.38)$ \\
$\quad$ secondary & $0.92(0.52,1.63)$ & $0.96(0.54,1.72)$ \\
$\quad$ university & $1.06(0.54,2.06)$ & $1.06(0.56,2.01)$ \\
BMI $\geq 25 \mathrm{~kg} / \mathrm{m}^{2}\left(\right.$ versus BMI $\left.<25 \mathrm{~kg} / \mathrm{m}^{2}=0\right)$ & $1.80(1.54,2.10)$ & $1.07(0.86,1.34)$ \\
Abdominal obesity $($ versus no $=0)$ & $2.58(2.18,3.06)$ & $2.49(2.00,3.10)$ \\
\hline
\end{tabular}

* Adjusted OR controlled for age, area of residence, education, geographic region, BMI status, and abdominal obesity; abdominal obesity: waist circumference $\geq 90 \mathrm{~cm}$ in male and $\geq 80 \mathrm{~cm}$ in female.

\section{Discussion}

This study added more information on characteristics of individuals with coexistence of diabetes and hypertension in Thai population. A half of the people with diabetes also had hypertension and about $14 \%$ of hypertensive patients had diabetes. The prevalence of $3.2 \%$ of the coexistence corresponds to an estimated 1.5 million of Thai population having both conditions. After controlling for covariates, patients with the coexistence of diabetes and hypertension were likely to be older, having lower education and abdominal obesity. There were limited data on prevalence of the coexisting conditions in Asian populations. Although the prevalence of diabetes or hypertension in Thai population was comparable to that of other Asian countries [12], it is unclear whether the prevalence of the coexistence of both conditions is different from those of other Asian populations. Further studies of this issue might be warrant.

The coexistence of diabetes and hypertension increases risk of cardiovascular diseases $[7,13]$, renal complications, and retinopathy [7]. Randomized control trial studies demonstrated that aggressive control of blood pressure and diabetes could improve the CVD outcomes [14]. Therefore, early detection and control of the coexisting of the disease are essential. However, the present study revealed that awareness of the coexistence of both conditions was very low with less than $30 \%$ of individuals with both conditions being treated and less than $10 \%$ of the conditions being simultaneously controlled. The findings suggested that over 1 million individuals with both conditions were not detected and treated for their conditions.

Awareness of diabetes, hypertension and coexistence of both were lower in men than in women. This might reflect that men are less likely to seek health care and less health concern compared to women. This finding is consistent with the national survey data showing the higher health care utilization among women than men [15]. This finding suggests that health education program should be focused more on men.

The high proportion of having hypertension in patients with diabetes $(78.4 \%)$ had been reported in a study using the data from the Thai diabetes registry [16]. The proportion found in this study was lower than that of the registry data, because the cases in the registry were from the tertiary care hospitals, where severe cases of diabetes were more likely to be found. However, the proportion of hypertension in patients with diabetes in this study was higher than that of the United Kingdom prospective diabetes study (UKPDS), which reported the proportion of $39 \%[17,18]$. The proportion of diabetes among hypertensive patients in this study was slightly lower than what found in the US where the proportion of individuals with hypertension having diabetes was 19.8\% [19]. These findings are consistent with previous review [13] in that approximately half of the diabetes patients have hypertension, and hypertension was about twice as frequent in individuals with diabetes compared to those without diabetes.

BMI is a measure of total obesity and abdominal obesity is an indicator for abdominal fat deposition. This study found that abdominal obesity was a stronger risk factor for the coexistence of diabetes and hypertension. This finding was consistent with many studies and review on evidence of WC being a stronger risk factor for cardiovascular diseases and metabolic syndrome as compared to BMI [20-23]. However, some recent studies argued that the evidence to replace BMI with waist circumference for clinical or public health practice has not been strong enough [24, 25]. More research, particularly in Asian populations, is needed to confirm whether measuring abdominal obesity should replace BMI in surveillance of cardiovascular risk factors.

Other factors associated with the coexistence included education level less than 6 years. In a previous study we also reported that hypertension was more prevalent among those with lower education [5]. It is possible that those with lower education were at high risk, because they might have worse unhealthy lifestyles. In those with inadequate control either diabetes or hypertension might lead to the development of the other condition. A study reported that patients with hypertension are 2.5 times more likely to develop diabetes compared to those with normotension [13].

The strength of this study includes having large sample size and being a representative data that allows the analysis of each condition and the coexistence. Some limitations of the present study should be mentioned. First, the present 
study might underestimate the true prevalence of diabetes, since only FPG was used. Two-hour glucose tolerance test was reported to be more accurate in detection of undiagnosed diabetes compared to measurement of fasting plasma glucose; however, FPG test was more feasible to perform in field survey [26]. Second, the measurement of blood pressure could be subject to overestimation due to the effect of white coat hypertension. However, the measurement was done according to the standard protocol for blood-pressure measurement and the procedure was done in the community, so this effect might be minimal. Third, the cross-sectional design might preclude drawing conclusion about cause effect relationship between risk factors and the comorbidity.

The implication of this study is that the health care system should be designed to strengthen comprehensive health care of coexistence of diabetes and hypertension in order to increase detection, treatment, and control of those affected. In addition, individuals with obesity or those with low educational levels were at higher risk and should be targeted.

\section{Conclusion}

Patients with diabetes or hypertension should be screened for coexistence of another condition, and they should be promoted to have weight control in order to prevent the comorbidity. More stringent control of plasma glucose and blood pressure among these patients should be applied.

\section{Acknowledgments}

This study was supported by the Bureau of Policy and Strategy, Ministry of Public Health, the National Health Examination Survey Office, Health System Research Institute, and the National Health Security Office, Thailand. The authors thank Professor Dr. Amnuay Thithapandha, Mahidol University for his help in editing the paper.

\section{References}

[1] W. Aekplakorn, J. Abbott-Klafter, A. Premgamone et al., "Prevalence and management of diabetes and associated risk factors by regions of Thailand: third National health examination survey 2004," Diabetes Care, vol. 30, no. 8, pp. 2007-2012, 2007.

[2] Ministry of Public Health, Thailand Health Profile 2005-2006, Bureau of Policy and strategy, Ministry of Public Health, Nonthaburi, Thailand, 2007.

[3] J. Stamler, O. Vaccaro, J. D. Neaton, and D. Wentworth, "Diabetes, other risk factors, and 12-yr cardiovascular mortality for men screened in the multiple risk factor intervention trial," Diabetes Care, vol. 16, no. 2, pp. 434-444, 1993.

[4] A. H. Mokdad, E. S. Ford, B. A. Bowman et al., "Diabetes trends in the U.S.: 1990-1998," Diabetes Care, vol. 23, no. 9, pp. 1278-1283, 2000.

[5] W. Aekplakorn, J. Abbott-Klafter, P. Khonputsa et al., "Prevalence and management of prehypertension and hypertension by geographic regions of Thailand: the third National health examination survey, 2004," Journal of Hypertension, vol. 26, no. 2, pp. 191-198, 2008.
[6] W. Aekplakorn, "Prevalence, treatment, and control of metabolic risk factors by BMI status in Thai adults: National health examination survey III," Asia-Pacific Journal of Public Health, vol. 23, no. 3, pp. 298-306, 2011.

[7] A. V. Chobanian, G. L. Bakris, H. R. Black et al., "The seventh report of the joint National committee on prevention, detection, evaluation, and treatment of high blood pressure: the JNC 7 report," The Journal of the American Medical Association, vol. 289, no. 19, pp. 2560-2572, 2003.

[8] Report of a WHO Expert Committee, "Physical status: the use and interpretation of anthropometry," WHO Technical Report 854, World Health Organization, Geneva, Switzerland, 1995.

[9] American Diabetes Association, "Standards of medical care in diabetes-2010,” Diabetes Care, vol. 33, 1, pp. S11-S61, 2010.

[10] Ministry of Public Health, Thai Clinical Practice Guidelines for Diabetes, Ministry of Public Health, Bangkok, Thailand, 2001.

[11] Asia-Pacific Steering Committee and J. Bassett, The Asia Pacific Perspective: Redefining Obesity and Its Treatment, World Health Organization, International Association for the Study of Obesity, International Obesity Task Force, Melbourne, Australia, 2000.

[12] J. C. N. Chan, V. Malik, W. Jia et al., "Diabetes in Asia: epidemiology, risk factors, and pathophysiology," The Journal of the American Medical Association, vol. 301, no. 20, pp. 21292140, 2009.

[13] T. W. Gress, F. J. Nieto, E. Shahar, M. R. Wofford, and F. L. Brancati, "Hypertension and antihypertensive therapy as risk factors for type 2 diabetes mellitus," The New England Journal of Medicine, vol. 342, no. 13, pp. 905-912, 2000.

[14] A. I. Adler, I. M. Stratton, H. A. W. Neil et al., "Association of systolic blood pressure with macrovascular and microvascular complications of type 2 diabetes (UKPDS 36): prospective observational study," British Medical Journal, vol. 321, no. 7258, pp. 412-419, 2000.

[15] The 2004 Health and Welfare Survey Report, National Statistical Office, Ministry of Information and Communication Technology, Bangkok, Thailand, 2004.

[16] P. Bunnag, N. Plengvidhya, C. Deerochanawong et al., "Thailand diabetes registry project: prevalence of hypertension, treatment and control of blood pressure in hypertensive adults with type 2 diabetes," The Journal of the Medical Association of Thailand, vol. 89, supplement 1, pp. S72-S77, 2006.

[17] B. Williams, "The hypertension in diabetes study (HDS): a catalyst for change," Diabetic Medicine, vol. 25, no. 2, pp. 1319, 2008.

[18] R. Turner, I. Stratton, V. Fright, R. Holman, S. Manley, and C. Cull, "Hypertension in diabetes study (HDS): I. Prevalence of hypertension in newly presenting type 2 diabetic patients and the association with risk factors for cardiovascular and diabetic complications," Journal of Hypertension, vol. 11, no. 3, pp. 309-317, 1993.

[19] B. M. Egan, Y. Zhao, and R. N. Axon, "US trends in prevalence, awareness, treatment, and control of hypertension, 19882008," The Journal of the American Medical Association, vol. 303, no. 20, pp. 2043-2050, 2010.

[20] G. Vazquez, S. Duval, D. R. Jacobs Jr., and K. Silventoinen, "Comparison of body mass index, waist circumference, and waist/hip ratio in predicting incident diabetes: a metaanalysis," Epidemiologic Reviews, vol. 29, no. 1, pp. 115-128, 2007.

[21] W. Aekplakorn, V. Kosulwat, and P. Suriyawongpaisal, "Obesity indices and cardiovascular risk factors in Thai adults," International Journal of Obesity, vol. 30, no. 12, pp. 1782-1790, 2006. 
[22] T. Pischon, H. Boeing, K. Hoffmann " et al., "General and abdominal adiposity and risk of death in Europe," The New England Journal of Medicine, vol. 359, no. 20, pp. 2105-2120, 2008.

[23] V. Hirani, P. Zaninotto, and P. Primatesta, "Generalised and abdominal obesity and risk of diabetes, hypertension and hypertension-diabetes co-morbidity in England," Public Health Nutrition, vol. 11, no. 5, pp. 521-527, 2008.

[24] A. E. Taylor, S. Ebrahim, Y. Ben-Shlomo et al., "Comparison of the associations of body mass index and measures of central adiposity and fat mass with coronary heart disease, diabetes, and all-cause mortality: a study using data from 4 UK cohorts," American Journal of Clinical Nutrition, vol. 91, no. 3, pp. 547-556, 2010.

[25] P. Sebo, S. Beer-Borst, D. M. Haller, and P. A. Bovier, "Reliability of doctors' anthropometric measurements to detect obesity," Preventive Medicine, vol. 47, no. 4, pp. 389-393, 2008.

[26] C. C. Cowie, K. F. Rust, E. S. Ford et al., "Full accounting of diabetes and pre-diabetes in the U.S. population in 1988-1994 and 2005-2006," Diabetes Care, vol. 32, no. 2, pp. 287-294, 2009. 


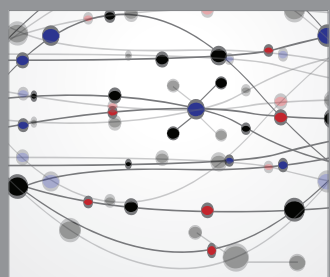

The Scientific World Journal
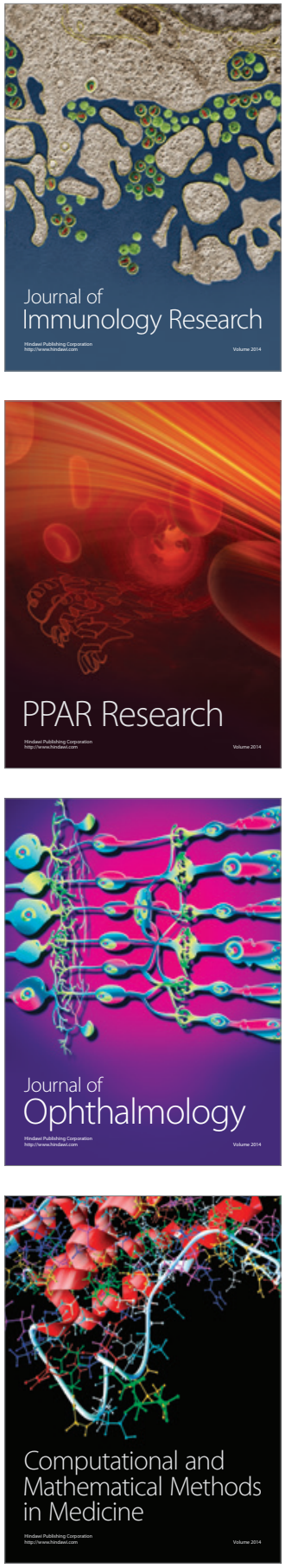

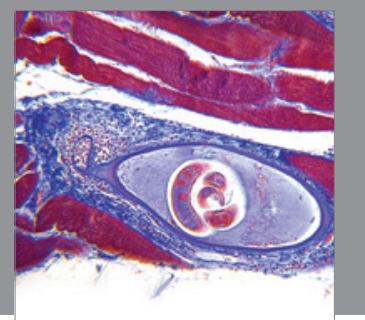

Gastroenterology

Research and Practice
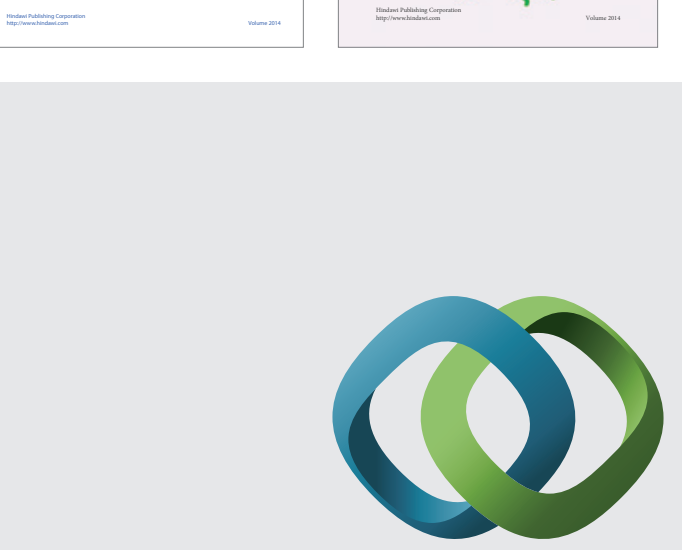

\section{Hindawi}

Submit your manuscripts at

http://www.hindawi.com
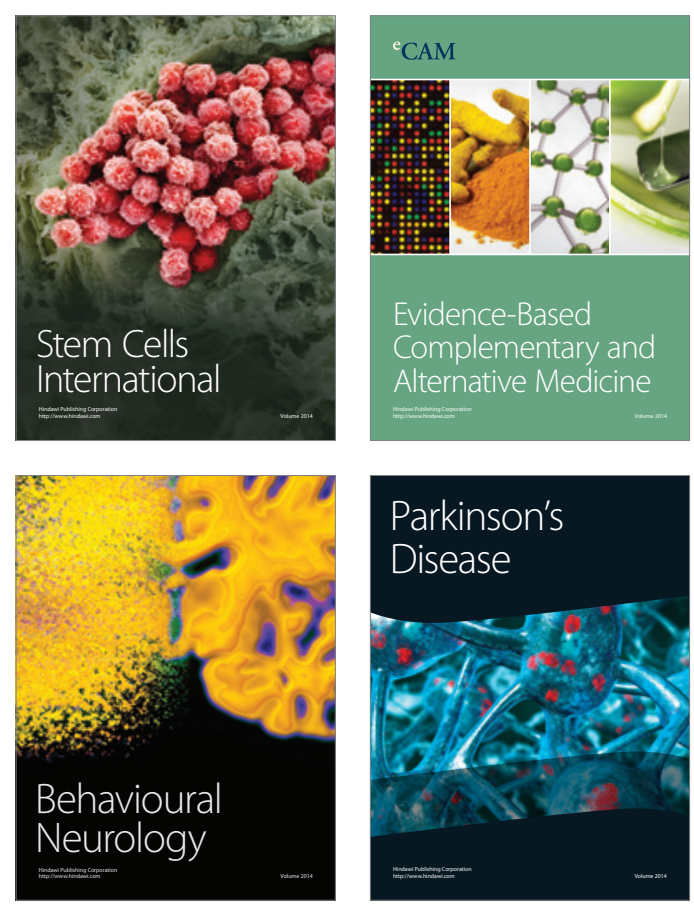

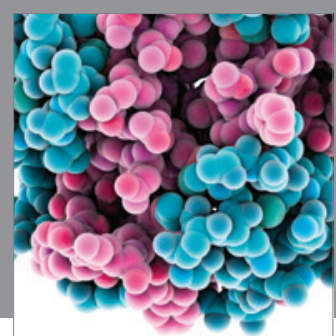

Journal of
Diabetes Research

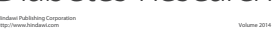

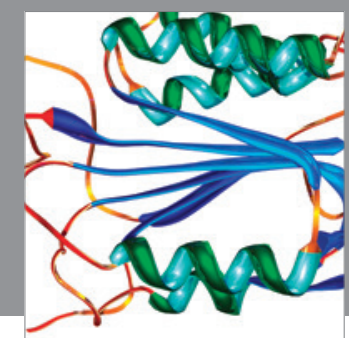

Disease Markers
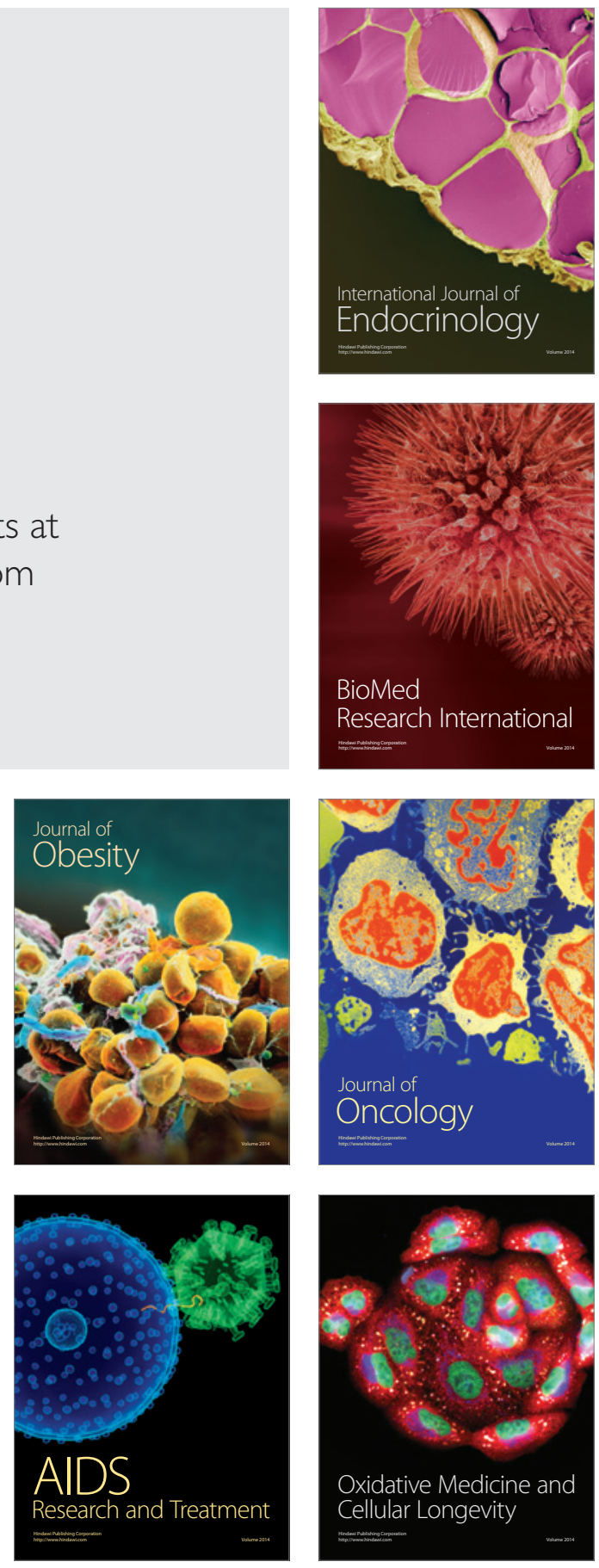